\title{
Exploring the Capabilities of Online Facilitation to bridge the Instructional Gaps in Open and Distance Learning Delivery in Nigeria
}

\author{
Lukuman Kolapo Bello \\ Directorate of Learning Content Management System, National Open University of Nigeria, Plot 91, \\ Cadastral Zone, Jabi, Abuja, Nigeria \\ E-mail of the corresponding author: adebello4@gmail.com
}

\begin{abstract}
Amid the increasing popularity of online learning worldwide, efforts are being made to close the gaps within the system's critical instructional elements (teachers, students, and learning resources). Online facilitation has been touted as a veritable platform that allows seamless interaction between distance learners and their tutors. However, some student-related factors could hinder effective online facilitation at this level of education. Therefore, this study investigated the impact of perceived usefulness and perceived ease of use on students' acceptance of online facilitation, especially within the Open and Distance Learning (ODL) system of education. The study adopted a mixed-method research design to generate qualitative and quantitative data from the participants. A total of 1193 distance learners across seven faculties participated in the study. The web-based survey results showed that the level of acceptance of online facilitation among students was high, with a weighted average of 4.0. The level of perceived ease of use and perceived usefulness of students were also high with weighted averages of 3.8 and 4.1 respectively. The p-values of 0.002 and 0.02 indicated that there were significant effects of students' perceived ease of use and perceived usefulness respectively on the level of acceptance of online facilitation as an interactive platform in ODL instructional delivery. Based on these findings, it was recommended that stakeholders need to demystify the online facilitation process and make it user-friendly through adequate training to equip distance learners with the requisite competencies to navigate the platform.
\end{abstract}

Keywords: Perceived ease of use, perceived usefulness, online interaction, learners engagement, instructional gaps.

DOI: $10.7176 / \mathrm{JEP} / 12-3-20$

Publication date: January $31^{\text {st }} 2021$

\section{Introduction}

Open and Distance Learning (ODL) is practically characterized by the physical separation between tutors and students. This separation reduces the expected level of interaction within the learning space. The strategic importance of interaction among students, teachers, and learning content has been well established and referenced in many theories of education, especially constructivism learning theory (Picciano, 2017). The lack of sociophysical interaction could trigger unprecedented complexities and depressing experiences in the instructional process as compared with the traditional system of education. Brown (2017) affirms that learning in a brick-andmortar institution presents students with the opportunity to meet with people from diverse backgrounds and interact with learning materials, unlike distance learning that limits students to classes and learning materials that are based online. When learners participate in ODL, they are more likely to face daunting difficulty getting in touch with their tutors/instructors and learning materials. Though students can explore the possibilities provided by email and other messaging services, the platforms definitely lack the capabilities to get them the immediate feedback they would get if they were able to sit down with their instructors in the conventional classroom, (Hutt, 2017; Abimbade, Adedoja, Fakayode, \& Bello, 2019).

\section{Leveraging the Capabilities of Online Facilitation to bridge the Instructional Gaps in ODL}

The temporal and geographical separation among the critical instructional elements in ODL have necessitated the need for educational stakeholders to leverage the affordances provided by technology to bridge these instructional gaps and engage students in continuous interaction within the learning space. With the increasing the pressure to provide quality online learning experiences for distance learners (Thompson \& MacDonald, 2005), many ODL institutions across the globe are becoming cognizant of the need to support the social dimension of learning, which is practically based on interaction among instructional elements (Abimbade, Akinyemi, Bello, \& Mohammed, 
2017; Abimbade, Bello, \& Esobi, 2020). This has resulted to the adoption of practices that foster a sense of community, which propels a sense of belonging and interactivity in an online environment (Magjuka, Bonk, \& Lee, 2007; Hew, 2015). The advancement in technology is rapidly increasing the level of interaction among instructors, learners and learning materials. This makes online facilitation an integral part of the modern ODL system of education across the globe.

Online facilitation can generally be described as the act of managing the learners and learning resources through an online learning platform. Facilitation is the systematic process of managing the communication of others in online medium (Coghlan 2001). Online facilitation is rapidly creating a pedagogical shift in the mode of engagement, collaboration, interaction, and discussion in online learning. Basically, online facilitation is a pedagogical term that emphasises student-centered approaches to teaching within online space, where the teacher moves from being a "sage on the stage" to a "guide on the side". Scholars have argued that online facilitation strengthens relationships among the tutors, distance learners and learning resources (Adesina, 2020). It remains an ODL instructional delivery approach that requires competent personnel with appropriate skills and favourable attitude to moderate teaching-learning process in virtual learning environments (Motladi, 2014). This intervention is considered as an emerging instructional delivery medium, which engenders active interaction among critical instructional elements in ODL. The online learning environment has a liberating effect on distance learners and provides an appropriate platform for facilitators to encourage students to take control of their own learning. It represents a major paradigm shift in ODL instructional process and has caused fundamental changes in education systems worldwide. This makes it an indispensable tool in the functional ODL instructional process. Online facilitation could be carried out in synchronous and asynchronous formats. Synchronous online facilitation has to do with real-time interaction between facilitators and learners using Learning Management Systems (LMSs) like Blackboard, MOODLE, Canvass among other platforms. On the other hand, asynchronous online facilitation leverages the capabilities of discussion tools like chat option and discussion forum to engage learners and stimulate interaction before or after the synchronous session.

As the foremost ODL institution in the country, the National Open University of Nigeria (NOUN) recently introduced online facilitation into the instructional delivery process, with a view to engendering active interaction and engagement with the learning content. This has been a paradigm shift from the traditional mode of instructional delivery which involved uploading of course materials in PDF format on the school website for students to download and read before examinations. In the last few years, many studies focused on the benefits derivable from online facilitation to ensure effective online teaching-learning process. A wealth of previous research has examined how online courses might be better designed to support students' engagement in instructional content based on some factors, including discussion group size (Hewitt \& Brett, 2007), facilitation methods (Wise \& Chiu, 2011), and course length (Ferguson \& DeFelice, 2010). However, what remains unclear is the impact of learner-related factors in determining the success of online learning, especially at the higher level of education. As with the introduction of other technology-related devices/platforms in the instructional process, scholars have argued that effective technology use could largely be a function of the levels of acceptance, perceived relevance and aspiration of the users (Bello \& Hamzat, 2020; Ogunlade \& Bello, 2019).

\subsection{Distance Learners' Acceptance of Online Facilitation}

Students' level of acceptance has been touted as a significant factor that could determine effective use of technology to enhance instructional delivery. Since online facilitation is still relatively new in the context of the Nigerian higher education system, it becomes imperative to investigate students' rate of acceptance of this technology-mediated instructional delivery mode, with a view to understanding possible factors that could influence its successful integration into the ODL system. Distance learners remain strategic stakeholders in ODL across the world and their level of acceptance of online facilitation could go a long way in determining the effective implementation of this mode of instructional delivery.

Technology Acceptance Model has been used to explain the intention to use technology among different categories of users. Scholars have also adopted TAM variables to predict the level of use of technology within the learning space. TAM, proposed by Davis (1989), has high reliability and validity as reported in Adams (1992). According to this model, the two major constructs that could determine behavioural intention to use technology are perceived ease of use (PEOU) and perceived usefulness (PU). PEOU refers to the extent a user believes that using a particular technology platform or device would be seamlessly free from difficulty, while PU is the degree to which user believes that using a specific technology-related device would improve performance on the job. In this context, perceived ease of use refers to the extent to which distance learner believes that participating in online facilitation 
would be free from any form of difficulties or challenges, while perceived usefulness is the degree to which distance learner agrees that online facilitation would improve understanding of instructional content, interaction and learning outcomes at the end of instruction.

TAM has been widely applied in diverse contexts within and outside instructional settings. For instance, Shroff, Deneen, \& $\mathrm{Ng}$ (2011) examined the impact of PEOU on students' behavioral intention to use an electronic portfolio system. The result indicated that PEOU had a significant impact on learners 'attitudes towards usage and acceptance of electronic portfolio system. Wu, \& Chen, (2017) affirmed that users' level of acceptance predicted intention to use and actual use of e-learning system, social media, and massive open online courses (MOOCs) within the instructional setting. Arbaugh \& Duray, (2002) affirmed that the more learners' PEOU and PU improve concerning course delivery media, such as course websites and file transmitting software, the more their attitudes changed positively toward e-learning. Consequently, this propelled their learning experiences and satisfaction and increased the rate of acceptance of this medium of instructional delivery.

For the purpose of this study, TAM constructs were adapted to measure the level of acceptance to participate in online facilitation among distance learners at the National Open University of Nigeria. It is expected that the introduction of this medium of instructional delivery could drastically alter students' learning styles, in terms of timing, planning, learning resources, and financial implication. Students might find it extremely difficult to adjust to this new learning approach. Thus, the intention was to measure the influence of perceived ease of use and perceived usefulness on distance learners' level of acceptance to participate in online facilitation. This could determine the successful implementation of online facilitation within the ODL setting.

\subsection{Research Questions}

i. What is the extent of NOUN students' acceptance of online facilitation as an acceptable medium for learning?

ii. What is the NOUN students' level of perceived ease of use of online facilitation as a medium to learn and interact?

iii. What is the extent of students' level of perceived usefulness of online facilitation as a medium of instruction in NOUN?

iv. Is there any impact of students' perceived ease of use on their acceptance of online facilitation as a medium of instruction?

v. Is there any effect of students' perceived usefulness on their acceptance of online facilitation as a medium of instruction?

vi. What are the instructional benefits of online facilitation at the National Open University of Nigeria?

vii. What are the challenges hindering effective participation of students in online facilitation at the National Open University of Nigeria?

\section{Methodology}

\subsection{Research Design}

The study adopted a mixed-method research design that involved the collection of quantitative and qualitative data from the respondents. Questionnaire on students' level of acceptance to participate in online facilitation was used to generate quantitative data while in-depth interview was used to gather qualitative data for the study. These instruments were made available online to the students at the end of six weeks facilitation exercise.

\subsection{Sample and Sampling Technique}

All the students in the institution form the population for the study. The sample cuts across all seven faculties at the National Open University of Nigeria. These include faculties of Education, Sciences, Social Sciences, Health Sciences, Law, Agricultural Sciences and Management Sciences. Total enumeration sampling technique was used to select distance learners, who completed the online survey and open-ended interview guide to generate qualitative and quantitative data for the study. The survey was conducted after the students had participated in the online 
facilitation process for six weeks. At the end of the exercise, 1193 students completed the online survey and this constitutes the sample for the study.

\subsection{Instruments}

The instrument consists of sections A, B, C, and D. Section A has to do with participant's background information while Section B comprises 10 items on acceptance of online facilitation. Section C and D measure perceived ease of use and perceived usefulness of online facilitation respectively. The questionnaire is measured on 5-Likert scale of Strongly Agree (SA), Agree (A), Neutral (N), Disagree (D) and Strongly Disagree (SD). This instrument was administered to 30 students, who were not part of the study to test the reliability. The Cronbach coefficient of 0.81 was obtained, which indicated that the instrument was consistently reliable. At the end of the exercise, interview guide on the challenges and benefits of participating in online facilitation was used to generate qualitative data from distance learners.

\subsection{Procedure}

This study examined the effect of perceived usefulness and perceived ease of use on distance learners' acceptance of online facilitation at the National Open University of Nigeria. The Directorate of Learning Content Management System (LCMS) is saddled with the responsibility of managing online facilitation through a learning platform called "mylearningspace". At the beginning of the session, the LCMS organized training for facilitators and students on the rudiments of online facilitation. Facilitators were trained on how to set-up the course pages and post discussion forum posts. They were also trained on how to upload learning resources like instructional videos and videos of previous facilitation sessions.

Students across study centers were trained on how to navigate the platform and access the courses. Students were encouraged to $\log$ in to www.mylearningspace.edu.net to participate in the online facilitation as indicated in figure 1 .

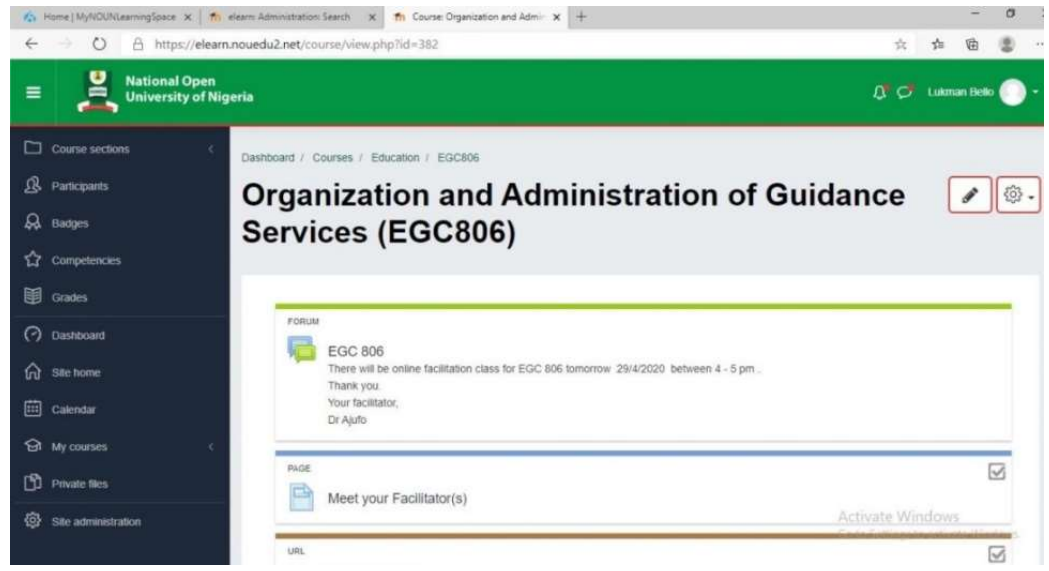

Figure 1: NOUN learning space

They were also guided on how to contribute to discussion forum posts and receive feedback from the facilitator. This intervention lasted six weeks for synchronous and asynchronous sessions. At the end of the exercise, students were encouraged to respond to web-based surveys on the level of acceptance, perceived ease of use, and perceived usefulness of online facilitation. The survey also included interview guide that sought to get students' views on the challenges and instructional benefits of online facilitation in the ODL environment.

\subsection{Data Analysis}

The data collected in the study was analyzed using statistical tools like percentages, mean, standard deviation and ANOVA, while the qualitative data was content analyzed. 


\section{Results}

\section{Research Question 1}

What is the extent of NOUN students' acceptance of online facilitation as an acceptable medium for learning?

Table 1: Acceptance of Online Facilitation among Distance Learners

\begin{tabular}{|l|l|l|l|}
\hline Faculty & Mean & Median & Standard Deviation \\
\hline Arts & 3.9 & 3.9 & 0.57 \\
\hline Education & 3.9 & 4.0 & 0.59 \\
\hline Health Sciences & 3.9 & 4.0 & 0.59 \\
\hline Law & 4.2 & 4.3 & 0.44 \\
\hline Management Sciences & 4.1 & 4.0 & 0.57 \\
\hline Sciences & 4.1 & 4.1 & 0.56 \\
\hline Social Sciences & 4.0 & 4.0 & 0.58 \\
\hline
\end{tabular}

Weighted average is 4.0

Information in Table 1 shows the mean score of the distance learners' level of acceptance of online facilitation across all the seven faculties in the institution. The weighted average is 4.0 , which indicates that the level of acceptance of online facilitation among the students is high. This means that many students are ready to participate in an online facilitation exercise. In order words, the participants show a high level of readiness to participate actively in the online facilitation, with a view to interacting with their colleagues and tutors.

\section{Research Question 2}

What is the NOUN students' level of perceived ease of use of online facilitation as a medium to learn and interact?

Table 2: Perceived Ease of Use of Online Facilitation among the Students

\begin{tabular}{|l|l|l|l|}
\hline Faculty & Mean & Median & Standard Deviation \\
\hline Arts & 4.2 & 3.0 & 0.63 \\
\hline Education & 3.8 & 3.1 & 0.71 \\
\hline Health Sciences & 3.9 & 3.3 & 0.68 \\
\hline Law & 3.6 & 3.2 & 0.37 \\
\hline Management Sciences & 3.4 & 3.5 & 0.62 \\
\hline Sciences & 3.8 & 3.5 & 0.62 \\
\hline Social Sciences & 3.9 & 3.3 & 0.60 \\
\hline
\end{tabular}

Weighted average is 3.8

Table 2 indicates the students' perceived ease of use of online facilitation at the National Open University of Nigeria. With a weighted average of 3.8, many students who participated in the study perceived online facilitation as a user-friendly and easy-to-use instructional delivery platform. This indicates that students consider online facilitation as a delivery platform that could easily be navigated to participate in learning activities. 


\section{Research Question 3}

What is the extent of students' level of perceived usefulness of online facilitation as a medium of instruction in ODL?

Table 3: Students' Perceived Usefulness of Online Facilitation

\begin{tabular}{|l|l|l|l|}
\hline Faculty & Mean & Median & Standard Deviation \\
\hline Arts & 4.0 & 4.0 & 0.58 \\
\hline Education & 3.9 & 3.9 & 0.55 \\
\hline Health Sciences & 4.0 & 4.0 & 0.55 \\
\hline Law & 4.4 & 4.3 & 0.32 \\
\hline Management Sciences & 4.1 & 4.1 & 0.57 \\
\hline Sciences & 4.1 & 4.1 & 0.53 \\
\hline Social Sciences & 4.1 & 4.1 & 0.57 \\
\hline
\end{tabular}

Weighted average is 4.1

Table 3 shows the level of perceived usefulness of online facilitation among distance learners. The weighted average is 4.1 , which suggests that the participants consider online facilitation as a useful instructional delivery mode that could promote engagement and collaboration with their colleagues and tutors from different parts of the country, regardless of spatial and temporal barriers.

\section{Research Question 4}

Is there any impact of students' perceived ease of use on their acceptance of online facilitation as the medium of instruction?

Table 4: ANOVA of the Effect of Perceived Ease of Use on Acceptance of Online Facilitation

\begin{tabular}{|c|c|c|c|c|c|c|}
\hline Source of Variation & $S S$ & $d f$ & $M S$ & $F$ & $P$-value & $F$ crit \\
\hline Between Groups & 8.178311 & 6 & 1.363052 & 3.349392 & 0.002816 & 2.106336 \\
\hline Within Groups & 474.9165 & 1167 & 0.406955 & & & \\
\hline Total & 483.0948 & 1173 & & & & \\
\hline
\end{tabular}

Table 4 shows the effect of students' perceived ease of use on their acceptance to participate in online facilitation exercise. With the p-value of 0.002 , it implies that there is a significant effect of students' perceived ease of use on the level of acceptance of online facilitation as an effective instructional delivery platform in ODL. In other words, perceived ease of use could be a crucial factor that could determine the acceptance of online facilitation among the students in the institution. This should be a strong factor to be considered in the planning and implementation of online facilitation, as an intervention to bridge the instructional gap between the students and their tutors.

\section{Research Question 5}

Is there any effect of students' perceived usefulness on their acceptance of online facilitation as a medium of instruction in NOUN? 
Table 5: ANOVA of the Impact of Students' Perceived Usefulness on the Acceptance of Online Facilitation

\begin{tabular}{|c|c|c|c|c|c|c|}
\hline Source of Variation & $S S$ & $d f$ & $M S$ & $F$ & $P$-value & $F$ crit \\
\hline Between Groups & 4.368103 & 6 & 0.728017 & 2.360002 & 0.028562 & 2.106471 \\
\hline Within Groups & 353.8284 & 1147 & 0.308482 & & & \\
\hline Total & 358.1965 & 1153 & & & & \\
\hline
\end{tabular}

Table 5 shows the impact of students' perceived usefulness on their level of acceptance to participate in online facilitation exercise. This suggests that perceived usefulness has a significant effect on the level of acceptance of online facilitation among the students. In other words, the level of acceptance of this instructional delivery mode could be a function of students' perceived usefulness.

\section{Discussion}

From the findings, there was a high level of acceptance of online facilitation intervention among NOUN students. The implication is that, distance learners who participated in the online facilitation considered the intervention as a viable platform that could bridge the instructional gaps between learners and their tutors. The participants were of the opinion that distance learners could be engaged in the instructional content and interact with their tutors, irrespective of temporal and spatial barriers within the learning space. It is important to note that lack of physical contact among the basic instructional elements (tutors, learners and learning resources) is one of the strong criticisms of ODL across the globe. Notwithstanding the increasing adoption of online learning across ODL institutions in the world, especially with the global health emergency like COVID-19 pandemic, skepticism surrounding its level of quality remains one of the major impediments as indicated by many faculty members. However, the advancement in internet technology has brought about Learning Management System (LMS) that could be used to manage the instructional process and engender active interaction between learners and tutors. Thus, the participants in this study might have recognized the capabilities of online facilitation to bridge the instructional gaps in the learning process and allow distance learners to interact with their tutors and peers from different parts of the world, regardless of spatial and temporal barriers. This has made online facilitation a positive response to improve the quality of online learning in particular and ODL system of education in general.

Apparently, this high level of acceptance among distance learners would improve their participation in online facilitation. This is well corroborated by Donkor (2011) who investigated the learners' acceptance and satisfaction regarding video lessons within the ODL learning space. The result indicated a positive relationship between students' level of acceptance and their readiness to use video lessons in online learning. In order words, the level of acceptance of online facilitation could be a determining factor to the effective participation of students in the process. This makes it imperative for stakeholders in ODL to consider the level of acceptance of this instructional delivery medium in the planning and implementation of online learning, especially at the higher level of education.

With a weighted average of 3.8, findings revealed that many students who participated in the study considered online facilitation as a user-friendly and easy-to-use instructional delivery platform that could bridge the gaps between distance learners and tutors. In essence, an online facilitation platform has been perceived as an instructional delivery channel that learners could easily navigate to participate in videoconferencing, discussion forum, submission of assignment and quiz. This could be as a result of the user-friendly nature of the MOODLE platform used for the facilitation process. The platform is an integrated tool that could be used to facilitate a wide range of online learning processes like interaction, collaboration, discussion, synchronous instruction, quiz and assessment. The platform is enriched with tools that would allow distance learners to participate effectively in the teaching-learning process, as obtainable in the face-to-face instructional setting. Therefore, learners who participated in the study were of the opinion that this platform is ease to use and does not require a high level of ICT competence. In a study on procedural learning through YouTube in a laboratory setting, Lee \& Lehto (2013) extended the existing TAM variables with YouTube self-efficacy, vividness, task technology and content richness to measure the users' satisfaction. The findings indicated that the extent of perceived ease of use of YouTube in a lab setting was high. It is noteworthy that online facilitation provides a veritable channel for seamless interaction with tutors and other students, notwithstanding the distance within the learning space. This might be a possible justification for the high level of perceived ease of use among distance learners, who participated in the study. 
Sumak, Hericko, \& Pusnik, (2011), affirm that perceived ease of use is a crucial factor that determines users' participation in technology-based activities.

There was also a high level of perceived usefulness of online facilitation as a medium of interaction within the instructional process. Distance learners believed that this intervention could assist them to participate actively in teaching-learning activities. This high level of perceived usefulness could be due to the affordances provided by online facilitation to promote engagement and interaction between distance learners and tutors. This mode of instructional delivery could be a perfect fit to bridge the instructional gaps in ODL system of education as learners can collaborate with their colleagues to execute instructional tasks, regardless of temporal and spatial barriers. This makes online facilitation a useful platform that promotes interaction, engagement and cross-fertilization of ideas, with a view to improving the quality of online learning across different regions of the world (Mbati \& Minnaar, 2015). This is in line with Abdullah \& Ward (2016), who found that users' perceived usefulness remains a potent factor that could determine technology use.

The findings showed that there was a significant effect of perceived ease of use on the rate of acceptance of online facilitation as an effective instructional delivery platform in ODL. The implication is that the way students perceive online facilitation as a user-friendly and flexible teaching-learning platform could determine, to an extent, their level of acceptance of this instructional delivery medium. Apparently, distance learners would prefer to use an intervention that requires minimum technological competence to navigate and interact with tutors and colleagues. Online facilitation is a technology-based instructional delivery medium and requires basic ICT skills. For instance, anyone with the skills to operate a mobile phone can easily participate in online facilitation. In fact, many of the students used mobile phones to participate in the exercise. This made the platform easy to navigate for students. Nagy, (2018) found that perceived ease of use had a significant impact on learning satisfaction among students in online video usage. In the same vein, Chung, Chen, \& Kuob (2015) affirmed that perceived ease of use had a direct effect on the behavioral intentions to use mobile English vocabulary learning resources in an online learning setting.

It was revealed that perceived usefulness had a significant impact on the level of acceptance of online facilitation among the students. This implies that the way students perceive online facilitation as an engaging platform that could assist them to actively interact with their tutors and colleagues determines, to an extent, their level of acceptance to participate in the process. This is well-encapsulated in the words of Traxler (2018) that new technologies facilitate greater interaction and collaboration, and students in an online learning environment would find these tools useful to participate actively in the teaching-learning process. This is corroborated by Seliaman \& Turki (2012), who used TAM variables to investigate Saudi university students' use of mobile devices to access course materials, search for information related to their disciplines, and participate in the discussion forum. Findings revealed that students' perceived usefulness of mobile learning significantly affected the rate of use of mobile devices to access course materials, search for information related to their disciplines, and participate in the discussion forum. In this wise, the LMS adopted by ODL institutions should, therefore, be set-up in a way that distance learners would recognize its usefulness in meeting their diverse learning needs and expectations.

In qualitative terms, comments from web-based interview indicated that students considered online facilitation as a veritable platform that engendered engagement and interaction among the students, especially as it strengthens the connection between distance learners and their tutors. One student remarked that "this medium allows us to relate directly with our lecturers, instead of relying solely on course materials". This implies that synchronous and asynchronous facilitation encourage seamless interaction within the instructional process and this could facilitate learning at this level of education. Another student commented that "online facilitation encourages immediate feedback within the system as students are able to ask questions and get immediate response from the tutor". It is important to note that the LMS like MOODLE is incorporated with tools that could provide adequate feedback within the instructional process. This is a positive response to bridge the instructional gaps within the learning space.

On the last note, findings suggested that students were faced with a myriad of infrastructural and instructional challenges to effectively participate in online facilitation. Distance learners commented that poor internet, irregular power supply, inadequate technical support and lack of awareness are some of the critical challenges that hindered the effective participation in the online facilitation exercise. One distance learner stated that "poor internet service and erratic power supply remain the most important factors that could hinder students' participation in the online facilitation". Another student commented that "many distance learners are not aware of the advantages of online facilitation exercise". Sadeghi (2019) asserts that poor internet access and the possibility of distraction while learning in isolation could be major factors hindering effective online learning across different countries in the world. In the same vein, Lloyd, Byrne, \& McCoy (2012) found that inadequate training, inadequate technology 
support, technology failures, and changing LMS software could be contributing factors to effective online learning. These challenges should, therefore, be considered in the planning and implementation of online facilitation for the effective teaching-learning process, especially at the higher level of education.

\section{Conclusion}

With the advancement in technological innovations to bridge the instructional gaps between distance learners and their tutors, online learning is increasingly becoming a positive response to the global quest for increased access to educational opportunities, especially during global health emergency like the COVID-19 pandemic and beyond. Online facilitation has been touted as a veritable platform to engage distance learners across geographical regions of the world, regardless of temporal and spatial barriers. To ensure effective online learning delivery, the National Open University of Nigeria recently introduced online facilitation to promote engagement and interaction with the students across the country and beyond. Thus, it becomes imperative to investigate the probable factors that could determine the extent of acceptance of this interactive mode of online instructional delivery among distance learners. This is with the view to ensuring that stakeholders are able to take informed decision in the quest to improve the quality of online learning in the country.

This study established the fact that distance learners considered online facilitation as a useful learning platform to interact with their tutors and colleagues from different countries of the world. Perceived usefulness and ease of use have also been identified to have significant effects on students' level of acceptance of online facilitation as an effective mode of instructional delivery. Therefore, stakeholders in ODL need to address the myriad of challenges confronting effective facilitation process as identified by the participants. This would have a long term effect on the quality of online learning in the country and across the world.

\section{References}

Abdullah, F. \& Ward, R. (2016), "Developing a General Extended Technology Acceptance Model For E-Learning (GETAMEL) by Analysing Commonly Used External Factors", Computers in Human Behaviour 56, 238256.

Abimbade, O., Adedoja, G. O., Fakayode, B \& Bello, L. (2019), "Impact of Mobile-Based Mentoring, Socioeconomic Background and Religion on Girls' Attitude and Belief towards Antisocial Behaviour (ASB)", British Journal of Educational Technology (BJET) 50(2), 638-654. https://doi.org/10.1111/bjet.12719

Abimbade, O., Akinyemi, A., Bello, L., \& Olusegun, M. (2018). Comparative effects of an individualized computer based instruction and a modified conventional strategy on students' academic achievement in organic chemistry. The Journal of Positive Psychology and Counselling.

Adams, M. (1992), "Cultural Inclusion in the American College Classroom", New Directions for Teaching and Learning 42(49), 5-17.

Adedoja, G., \& Abimbade, O. (2013, May). Social studies teachers' intention to use mobile phones as a support and tutorial tool for teaching. In 2013 IST-Africa Conference \& Exhibition (pp. 1-8). IEEE.

Adedoja, G., \& Oluwadara, A. (2016). Influence of Age and Training on Planning Instruction Using Mobiles Phones by Pre-service Social Studies Teachers. Science and Education, 3(1), 1-6.

Adesina, A. (2020), "Leveraging the Capabilities of Online Facilitation as an Interactive Mode of Instructional Delivery in Open and Distance Learning in Nigeria", Journal of Education and Practice 11(36), 106-114. www.iiste.org. DOI: 10.7176/JEP/11-36-12

Arbaugh, J. B. \& Duray, R. (2002), "Class Section Size, Perceived Classroom Characteristics, Instructor Experience, and Student Learning and Satisfaction with Web-Based Courses: A Study and Comparison of Two Online MBA Programs", Management Learning 33(3), 331-347. DOI: $10.1177 / 1350507602333003$

Bello, L. K. \& Hamzat, L. F. (2020), "Levels of Aspiration to Use Digital Tools and Performance in an Educational Technology Course", International Journal of Teacher Education and Professional Development 3(1).

Brown, C. (2017), "Advantages and disadvantages of distance learning". Retrieved from https://www.eztalks.com/elearning/advantages-and-disadvantages-of-distance-learning.html 
Chung, H., Chen, S. \& Kuob, M. (2015), "A Study of EFL College Students' Acceptance of Mobile Learning", Procedia - Social and Behavioral Sciences 176, 333 - 339 Available online at www.sciencedirect.com

Coghlan, M. (2002), "Facilitating Online Learning". [Online] Available: http://users.chariot.net.au/ michaelc/olfac.html.

Davies, D. (1989), "Perceived Usefulness, Perceived Ease of Use, and User Acceptance of Information Technology", MIS Quarterly 13 (3), 319-340.

Donkor, F. (2011), "Assessment of learner acceptance and satisfaction with video-based instructional materials for teaching practical skills at a distance", The International Review of Research in Open and Distributed Learning 12(5), 74-92. https://doi.org/10.19173/irrodl.v12i5.953

Esobi, I. C., Lasode, M. K., Anyanwu, C. I., Barriguete, M. F., Okorie, M. A., \& Lasode, D. O. Food Insecurity, Social Vulnerability, and the Impact of COVID-19 on Population Dependent on Public Assistance/SNAP: A Case Study of South Carolina, USA.

Esobi, I. C., Lasode, M. K., Anyanwu, C. I., Degbe, E., Barriguete, M. F., Okorie, M. A., ... \& Okegbe, S. (2020). Nutritional Impact of COVID-19 and Its Implications on Atherosclerosis. World, 8(1), 16-21.

Esobi, I.C., Lasode, M.K., \& Barriguete, M.O.F. (2020). The Impact of COVID-19 on Healthy Eating Habits. J Clin Nutr Heal, 1(1), 001-002.

Ferguson, J. M., \& DeFelice, A. E. (2010), "Length of online course and student satisfaction, perceived learning, and academic performance", The International Review of Research in Open and Distributed Learning 11(2), 73-84. http://dx.doi.org/10.19173/irrodl.v11i2.772

Gloria, A., \& Oluwadara, A. (2016). Design and development of Mobile Learning Lesson Plan (MLLP) template: A design relevant to African context. American Journal of Educational Research, 4(9), 658-662.

Hew, K.F. (2015), "Student Perceptions of Peer versus Instructor Facilitation of Asynchronous Online Discussions: Further Findings from Three Cases", Instructional Science 43, 19-38. https://doi.org/10.1007/s11251014-9329-2.

Hewitt, J., \& Brett, C. (2007), "The relationship between class size and online activity patterns in asynchronous computer conferencing environments", Computers \& Education 49, 1258-1271. https://doi.org/10.1016/j.compedu.2006.02.001

Hutt, M. (2017), "Top 10 disadvantages of distance learning". https://www.eztalks.com/elearning/top-10disadvantages-of-distance-learning.html

Lasode, M., Esobi, I., Anyanwu, C., \& Lasode, D. (2020). Assessing Urban Land use Change in New Braunfels, Texas from 2013 to 2020 .

Lee, D. \& Lehto, M. (2013), "User Acceptance of YouTube for Procedural Learning: An Extension of the Technology Acceptance Model", Computers \& Education 9, 193-208.

Lloyd, S., Byrne, M., \& McCoy, T. S. (2012), "Faculty-Perceived Barriers of Online Education", MERLOT Journal of Online Learning and Teaching 8(1), 32-44.

Magjuka, R. J., Bonk, C. J., \& Lee, S. (2007), "Does sense of community matter?", Quarterly Review of Distance Education 8, 9-24.

Mbati, L. \& Minnaar, A. (2015), "Guidelines towards the Facilitation of Interactive Online Learning Programmes in Higher Education", International Review of Research in Open and Distributed Learning 16 (2).

Motladi, A. (2014), "Competencies Required for the Facilitation of Online Learning Courses: An Online Teaching Assistants Competency-Based Approach", Mediterranean Journal of Social Sciences 5(23), 56-65 Doi:10.5901/mjss.2014.v5n23p1405

Nagy, J. (2018), "Evaluation of Online Video Usage and Learning Satisfaction: An Extension of the Technology Acceptance Model", International Review of Research in Open and Distributed Learning 19(1), 94-105.

Ogunlade, B. O. \& Bello, L. K.. (2019), "Pre-Service Teachers' Perceived Relevance of Educational Technology Course, Digital Performance: Teacher Perceived of Educational Technology", International Journal of Technology-Enabled Student Support Services 9(1), 41-53.

Oluwaseun, O., Tolulope, F., Lukuman, B., \& Ikechukwu, E.C. (2020). Improving Pre-service Teachers' Memory and Retention Using Durable Memory Strategies in an Instructional Technology Course. American Journal of Educational Research, 8(11), 847-855. 
Oluwadara, A., Kolapo, B. L., \& Esobi, I. C. (2020). Designing a Framework for Training Teachers on Mobile Learning in Sub-Sahara Africa.

Omilani Nathaniel, A., Ayo-Vaughan Adewunmi, F., \& Abimbade Oluwadara, A. Teachers' Oversight of Science Values That Promotes Effective Citizenship.

Picciano, A. G. (2017), "Theories and Frameworks for Online Education: Seeking an Integrated Model", Online Learning 21(3), 166-190. doi: 10.24059/olj. v21i3.1225

Sadeghi, M. (2019), "A Shift from Classroom to Distance Learning: Advantages and Limitations", International Journal of Research in English Education 4(1). www.ijreeonline.com. DOI: 10.29252/ijree.4.1.80

Seliaman, M. E. \& Turki, M. S. (2012), "Mobile Learning Adoption in Saudi Arabia", World Academy of Science, Engineering and Technology 69, 72-87.

Shroff, R. H., Deneen, C. C., \& Ng, E. M. W. (2011), "Analysis of the Technology Acceptance Model in Examining Students' Behavioural Intention to Use an E-Portfolio System, Australasian Journal of Educational Technology 27(4). https://doi.org/10.14742/ajet.940

Sumak, B., Hericko, M. \& Pusnik, M. (2011), "A Meta-Analysis of E-Learning Technology Acceptance: The Role of User Types And E-Learning Technology Types", Computers in Human Behaviour 27, 2067-2077.

Thompson, T. L., \& MacDonald, C. J. (2005), "Community Building, Emergent Design and Expecting the Unexpected: Creating a Quality E-learning Experience", Internet and Higher Education 8(3), 233-249. https://doi.org/10.1016/j.iheduc.2005.06.004

Traxler, J. (2018), "Distance Learning: Predictions and Possibilities", Educ. Sci, 8(1), 35-49. https://doi.org/10.3390/educsci8010035R5f

Wise, A. F., \& Chiu, M. M. (2011), "Analyzing Temporal Patterns of Knowledge Construction in a Role-Based Online Discussion", Computer-Supported Collaborative Learning 6, 445-470. https://doi.org/10.1007/s11412-011-9120-1

Wu, B., \& Chen, X. (2017), "Continuance Intention to Use MOOCs: Integrating the Technology Acceptance Model (TAM) and Task Technology Fit (TTF) model", Computers in Human Behaviour 67, 221-232. https://doi.org/10.1016/j.chb.2016.10.028. 